\title{
Management of Idiopathic Macular Telangiectasia Type 2
}

\author{
Alireza Khodabande - Ramak Roohipoor · Javad Zamani · \\ Masoud Mirghorbani (D) - Hamidreza Zolfaghari · Shahab Karami • \\ Bobeck S. Modjtahedi
}

Received: January 2, 2019 / Published online: February 20, 2019

(C) The Author(s) 2019

\section{ABSTRACT}

Macular telangiectasia type 2 (MacTel) is a relatively rare disease without established treatments. Although MacTel was previously considered a primarily vascular condition, the thinking on its pathogenesis has shifted to it now being considered principally a neurodegenerative disease. This has resulted in a subsequent change in the approach to treatment

Enhanced digital features To view enhanced digital features for this article go to https://doi.org/10.6084/ m9.figshare.7637177.

Electronic supplementary material The online version of this article (https://doi.org/10.1007/s40123019-0170-1) contains supplementary material, which is available to authorized users.

A. Khodabande $\cdot$ R. Roohipoor · J. Zamani · M. Mirghorbani $(\varangle) \cdot$ H. Zolfaghari · S. Karami Eye Research Center, Farabi Eye Hospital, Tehran University of Medical Sciences, Tehran, Iran e-mail: masoud_mirghorbani2016@yahoo.com

B. S. Modjtahedi

Department of Ophthalmology, Southern California Permanente Medical Group, Baldwin Park, CA, USA

B. S. Modjtahedi

Eye Monitoring Center, Kaiser Permanente

Southern California, Baldwin Park, CA, USA

B. S. Modjtahedi

Department of Research and Evaluation, Southern California Permanente Medical Group, Pasadena, CA, USA toward neuro-protection for the non-proliferative phase of this disease. Carotenoid supplementation has had mixed results. Ciliary neurotrophic factor (CNTF) has demonstrated some promising early results, but further study is necessary to determine its actual effect. Some structural improvements have been seen in the non-proliferative phase with oral acetazolamide but without accompanying functional improvement. Anti-vascular endothelial drugs have been studied and not found to have benefit in the non-proliferative phase of disease but have demonstrated significant structural and functional value in the treatment of secondary neovascularization. There is no level I evidence for the various proposed MacTel treatments, and efforts need to be directed toward conducting multicenter randomized trials to better understand possible treatments for this condition.

Keywords: Anti-vascular endothelial growth; Macular telangiectasia; Management; Retina

\section{INTRODUCTION}

Idiopathic macular telangiectasia type 2 (MacTel) is a rare entity characterized by bilateral telangiectasia and dilation of the retinal capillaries in the juxtafoveal area, located mainly temporal to the fovea. Patients suffer variable 
amounts of bilateral progressive vision loss. Other clinical findings include loss of macular transparency, which may often appear in the temporal juxtafoveal area, intraretinal crystalline deposits, propagation of brown pigmentcontaining cells along abnormal blood vessels, which may represent hyperplasia of retinal pigment epithelium (RPE), and redistribution of macular pigment with a highly characteristic pattern including a loss of pigment temporal to the fovea without a loss of pigment at or beyond $>6.5^{\circ}$ [1]. Irregular retinal structural clefts can be seen in optical coherence tomography (OCT) and can be mistaken for macular edema. End stages of this disease are characterized by outer retinal degeneration, atrophy, and scarring. Subretinal neovascularization occurs in a minority of patients and is a secondary event that can result in significant loss of vision [2-4]. Gass and Blodi categorized macular telangiectasia into five stages according to disease severity [3], but Yannuzzi et al. simplified the classification with a focus on clinical, therapeutic, and prognostic relevance: stages 1-4 were categorized as a non-proliferative phase with stage 5 as the proliferative phase with the evolution of the subretinal neovascular complex [5]. Although subretinal neovascularization is classified as stage 5 , it can present at any point during the natural evolution of disease and is not part of a stepwise progression of in MacTel.

Treatments for MacTel have gained increasing interest, which necessitates an updated review of the current literature. The management of retinal vascular disease has been revolutionized by anti-vascular endothelial growth factor (anti-VEGF) drugs, which have also been employed to treat the proliferative phase of MacTel; however, treatments for the non-proliferative phases of MacTel remain elusive [6]. Given increasing knowledge about the pathophysiology of MacTel, including the paradigm shift from considering it a vascular disease to a neurogenetic condition, and its translation into possible therapeutic interventions, this review seeks to categorize the recent literature while considering the level of evidence provided by each study for both structural and functional outcomes.

\section{OVERVIEW OF MACTEL}

MacTel was first reported in 1968 as a case of macular dysfunction secondary to retinal vascular disease [4]. The first systematic attempt to classify idiopathic macular telangiectasias, an ultimately diverse group of diseases, was done in 1982 [4]. In 1993, these conditions were classified into three groups and several subgroups [3], and by 2006 a simplified classification was proposed by Yannuzzi et al. in which MacTel patients were classified into two groups: aneurysmal telangiectasia (MacTel type I) and perifoveal telangiectasia (MacTel type II) [5]. The latter is the most common type [5]. In this review, the preferred nomenclature for macular telangiectasia type II is MacTel (in accordance with the MacTel Study Group [2]). MacTel affects both genders equally [7] and is highly likely to be genetically determined, which indicates it would be expected to be present from the earliest stages of retinal development [8]. The signs and symptoms of MacTel can be subtle, especially early in the disease course, and patients may not be diagnosed on routine examination. Initial symptoms have the highest incidence in the 5th and 6th decades [9]. Patients typically present with difficulty reading, metamorphopsia, and paracentral scotomas. Vision loss is slowly progressive, and best corrected visual acuity is preserved until late in the disease [9]. Newer imaging modalities have allowed for earlier detection of MacTel: blue light fundus reflectance (BLR), dual-wavelength autofluorescence (DWAF), optical coherence tomography (OCT), and optical coherence tomography angiography (OCTA) [10]; all represent important diagnostic tools. Prevalence data are limited by differences in methodology including imaging methods used; however, the reported prevalence is higher in older age groups, which may be due to more easily apparent fundus findings in older cohorts [11]. The pathophysiology of MacTel has been the subject of debate. Gass et al. initially suggested a vascular etiology based on the premise that vascular insufficiency and the consequent hypoperfusion of nutrients and oxygen cause retinal tissue injury and atrophy [3]; however, 
Powner et al. demonstrated that the vasculature of the deep plexus is dilated abnormally within the affected retina [12] and that these areas suffer from depletion of Muller cells [13]. The concept that MacTel is a primarily neurodegenerative process was born from imaging studies using OCT and scanning laser ophthalmoscopy (SLO) [14] that suggested that vascular anomalies were a secondary feature of the disease $[13,15]$. Muller cells play a key role in MacTel because they provide several critical functions for retina physiology including growth factor secretion, angiogenesis/antiangiogenesis, neurotransmitter metabolism, synaptogenesis, neuroprotection, and photoreceptor survival [16]. Although the loss of Muller cells is not exclusively responsible for the initiation of retinal injury in MacTel [15], the experimental ablation of Muller cells results in the retina undergoing several alterations including photoreceptor apoptosis, vascular telangiectasia formation, and intraretinal neovascularization, similar to what is seen in MacTel [17]. In the non-proliferative phase, neurodegeneration is the predominant event, which leads to decreased photoreceptor function, loss of inner retina integrity, vascular anomalies, fluid leakage, and subsequent slow progressive vision loss. If the retinal damage is severe enough to initiate hypoxic pathways leading to angiogenesis mediator release and neovascularization, patients enter the proliferative phase (Fig. 1). Understanding the cellular pathways responsible for disease progression represents the foundation for elucidating possible treatment options for MacTel.

\section{METHODS}

This systematic review was conducted according to the Preferred Reporting Items for Systematic Reviews and Meta-analyses (PRISMA), 2009.

This article is based on previously conducted studies and does not contain any studies with human participants or animals performed by any of the authors.

\section{Search Methods for Identifying Studies}

Two authors (Sh.K. and H.Z.) searched four databases including MEDLINE, SCOPUS, EMBASE, and Cochrane, for the following keywords: "macula*", "parafovea*", "telangiect*", and "mactel". The search results were confined to papers published from 2010 to 2018 , and the literature search was concluded on 1 October 2018. Although several studies had included both MacTel I and II, papers that included patients with type I MacTel were excluded from this analysis because of fundamental differences in the pathophysiologies of these diseases. The references of selected studies were evaluated to identify additional publications for review.

\section{Study Selection}

Studies examining the interventions for MacTel were included in this review. Papers were screened for relevancy in title and abstract by both primary reviewers. In case of disagreement, a third reviewer (J.Z.) would evaluate a study for suitable for inclusion. The final list of included studies was re-evaluated by J.Z. to ensure proper study selection. Only papers with full texts or abstracts in English were selected.

\section{Data Collection and Risk of Bias Assessment}

Selected studies were evaluated systematically to extract the data. Characteristics of included studies were analyzed including country of origin, year, study design, number of eyes or participants, follow-up time, and intervention employed. Results of both functional and structural outcomes were included in this analysis. Functional outcomes included: (1) the mean change in best corrected visual acuity (BCVA) and (2) microperimetry. Structural outcomes included: (1) the mean retinal thickness change measured by OCT, (2) changes in fluorescein angiography (FA) pattern, and (3) any retinal structure-related data such as cone density and areas of outer retinal layer breaks. 

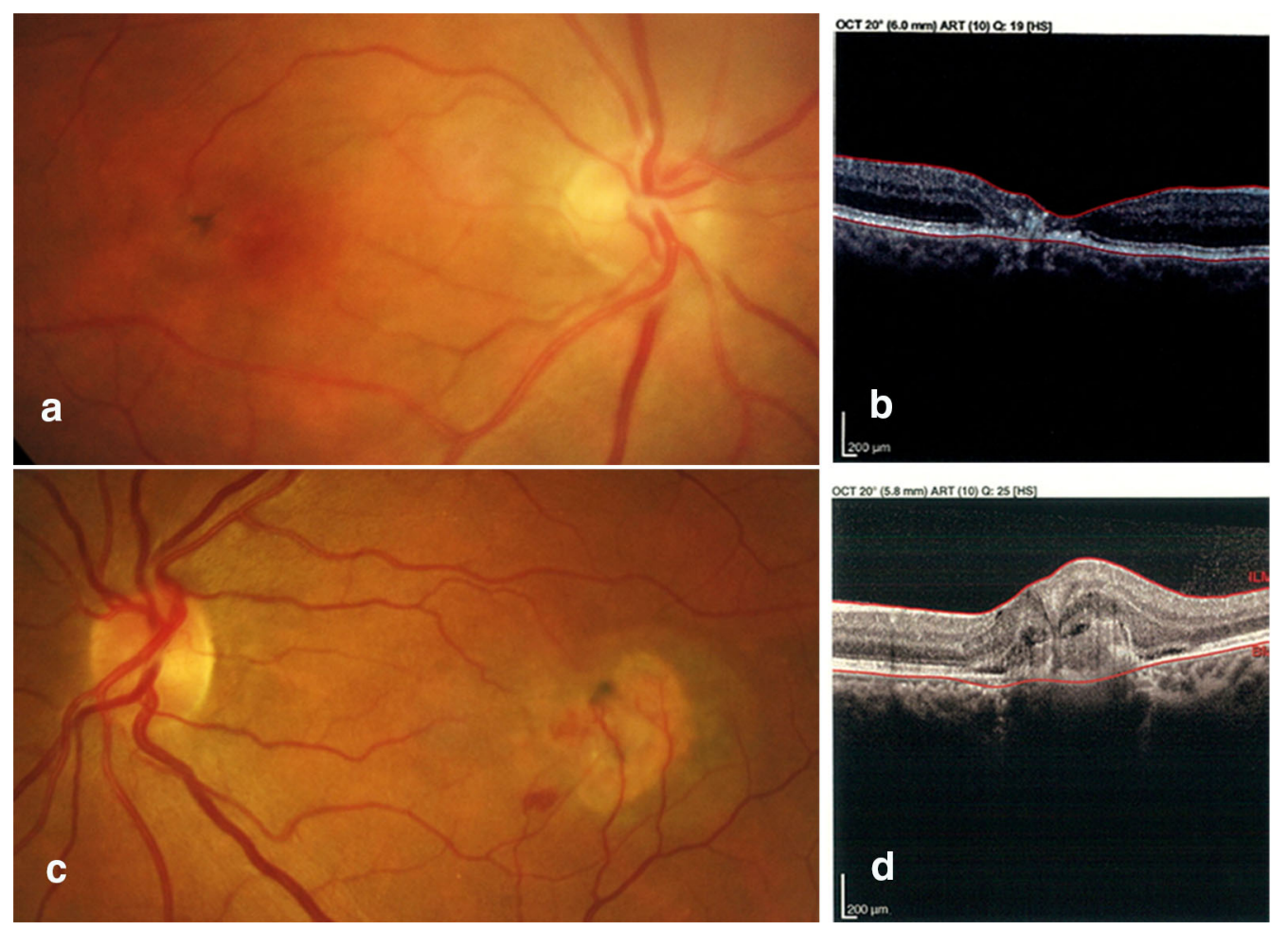

Fig. 1 Non-proliferative and proliferative phases of MacTel. 1: A 34-year-old male with bilateral progressive visual loss. Fundus photo of the right eye showed temporal parafoveal foci of retinal pigment epithelium (RPE) hyperplasia with foveal pigmentary change (a). Corresponding OCT demonstrated outer retinal layer atrophy and outward configuration of the inner retinal layers while

The panel rated the evidence provided by papers according to the British Centre for Evidence-Based Medicine guidelines [18]:

1. Level $I$ b evidence well-designed and wellconducted randomized clinical trials.

2. Level II evidence lower quality randomized studies, well-designed cohort studies.

3. Level III evidence well-designed case-control studies.

4. Level IV evidence lower quality cohort and case-control studies and case series.

* Note that case reports are not categorized.

\section{Data Synthesis and Analysis}

The efficacy of each intervention was scored based on functional and/or structural improvement. Interventions that achieved a BCVA gain the RPE layer appeared to be intact (b). 2: A 41-year-old male, a known case of MacTel with acute onset of vision loss in the left eye. Fundus photo and OCT imaging of the left eye showed not only RPE hyperplasia and pigmentary changes but also retinal and sub-retinal hemorrhages due to RPE disruption and choroidal neovascularization $(\mathbf{c}, \mathbf{d})$. Images courtesy of Dr. Hamid Riazi

or improvement in CMT (limited to those with statistically significant change when statistical analysis was done) were given a "plus" and interventions where patients had both BCVA gain and improvement in CMT received a "plusplus." Arresting progression of disease could be considered a positive outcome, given the typically unrelenting nature of MacTel; however, this analysis can be difficult to assess in smaller series with shorter follow-up times, and a positive outcome in this analysis was limited to those interventions where improvement was demonstrated to emphasize the most meaningful possible treatments. In long-term studies, only the results of the last visit were included in our analysis. 


\section{RESULTS}

The initial literature search found 1744 articles, of which 773 were duplicates. In the primary screening, 916 papers were deemed irrelevant, while 55 papers studied the treatment in MacTel type II. Two additional studies, found by reviewing references in the aforementioned papers, were included for further analysis. Of these 57 papers, 25 were excluded because they included both type I and type II macular telangiectasia patients. Thirty-two papers were included for final review and analysis for this project.

\section{Treatment of Non-Proliferative Phase}

Multiple interventions have been attempted over the past 3 decades. Focal laser photocoagulation was not found to confer any benefit and increased the risk of neovascularization [10], while photodynamic therapy (PDT) also did not show benefit in the non-proliferative phase of disease [19]. Two eyes received posterior juxtascleral administration of anecortave acetate (an angiogenesis inhibitor) as part of a pilot study and had stabilization of vision [20]; however, the development of the drug was later terminated by the manufacturer because of the emergence of newer more efficacious products.

\section{Anti-Vascular Endothelial Growth Factor (Anti-VEGF) Drugs}

Anti-VEGF drugs have extensively been studied as a treatment option for MacTel, including during the non-proliferative phase of the disease. Although three case-based studies [21-23] and one small retrospective studie [24] demonstrated improved functional and/or structural outcomes, larger retrospective studies with larger sample size did not recreate these findings $[25,26]$. Additionally, clinical trials $[27,28]$ failed to show visual benefit in patients treated with anti-VEGF. Although there was some reported improvement in central macular thickness, this was not sustained. Leakage on FA and increases in macular thickness occurred
5-6 months after the last injection. The development of poor outcomes and secondary sequela including loss of more than two lines of vision, paracentral scotomas, and subretinal vascular proliferation was reported more frequently in eyes treated with ranibizumab than control eyes in one prospective clinical trial years after the last injection [29, 30]. Despite some initially promising results from smaller studies, the weight of evidence from larger studies demonstrates that any structural improvement is transient and patients do not derive functional improvement with anti-VEGF drugs, which is consistent with the explained pathophysiology of the neurodegenerative phase of the disease. While it may be appealing to try to treat intraretinal spaces/cystic cavities with anti-VEGF therapy, it should be noted that VEGF may have a neuroprotective effect for the retina, which would be mitigated by anti-VEGF drugs. A summary of studies examining antiVEGF therapy for MacTel is presented in Table 1 [21-33]. Table 2 provides a summary of other treatments attempted for the non-proliferative phase of MacTel [25, 26, 34-42].

\section{Triamcinolone}

Intravitreal triamcinolone (IVT) was studied in a singular case that reported a significant improvement in vision and FA findings after 1 week that were sustained for 3 months [41]; however, no further studies examining IVT have been done.

\section{Laser Therapy}

YAG-laser doubled frequency laser therapy was studied by Meyer et al. in four eyes [25] and did not yield significant structural changes. Three years after laser, BCVA was $-1.2 \pm 1.5$ lines in the control group and $-1.9 \pm 1.9$ lines in the laser group, and after 5 years the change was $-2.0 \pm 2.4$ and $-2.8 \pm 2.2$ in the two groups, respectively. Statistical analysis was not done by the authors, but laser did result in what they deemed to be a non-significant reduction in vision. In one case report, a patient underwent indocyanine green dye-enhanced 


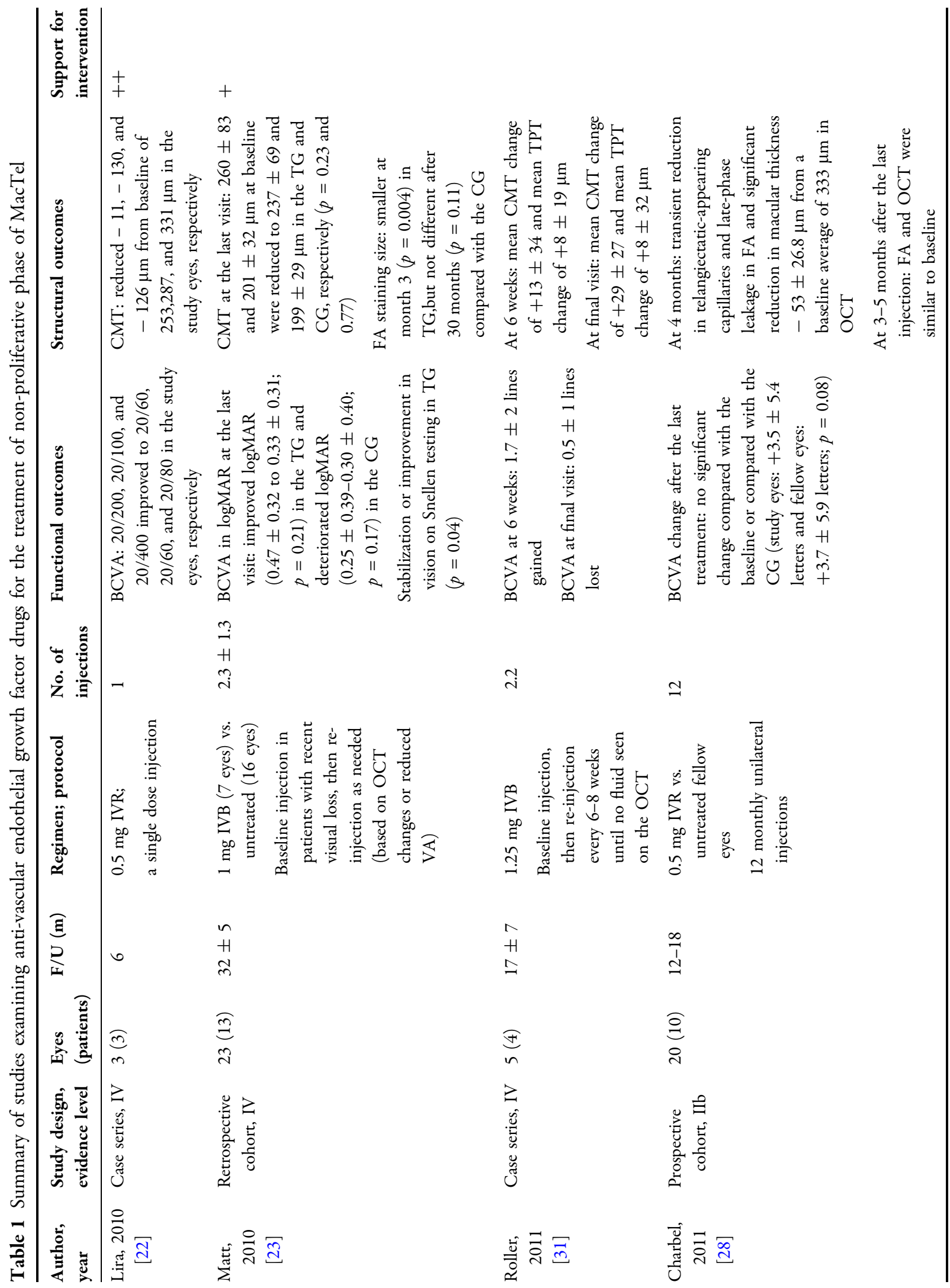




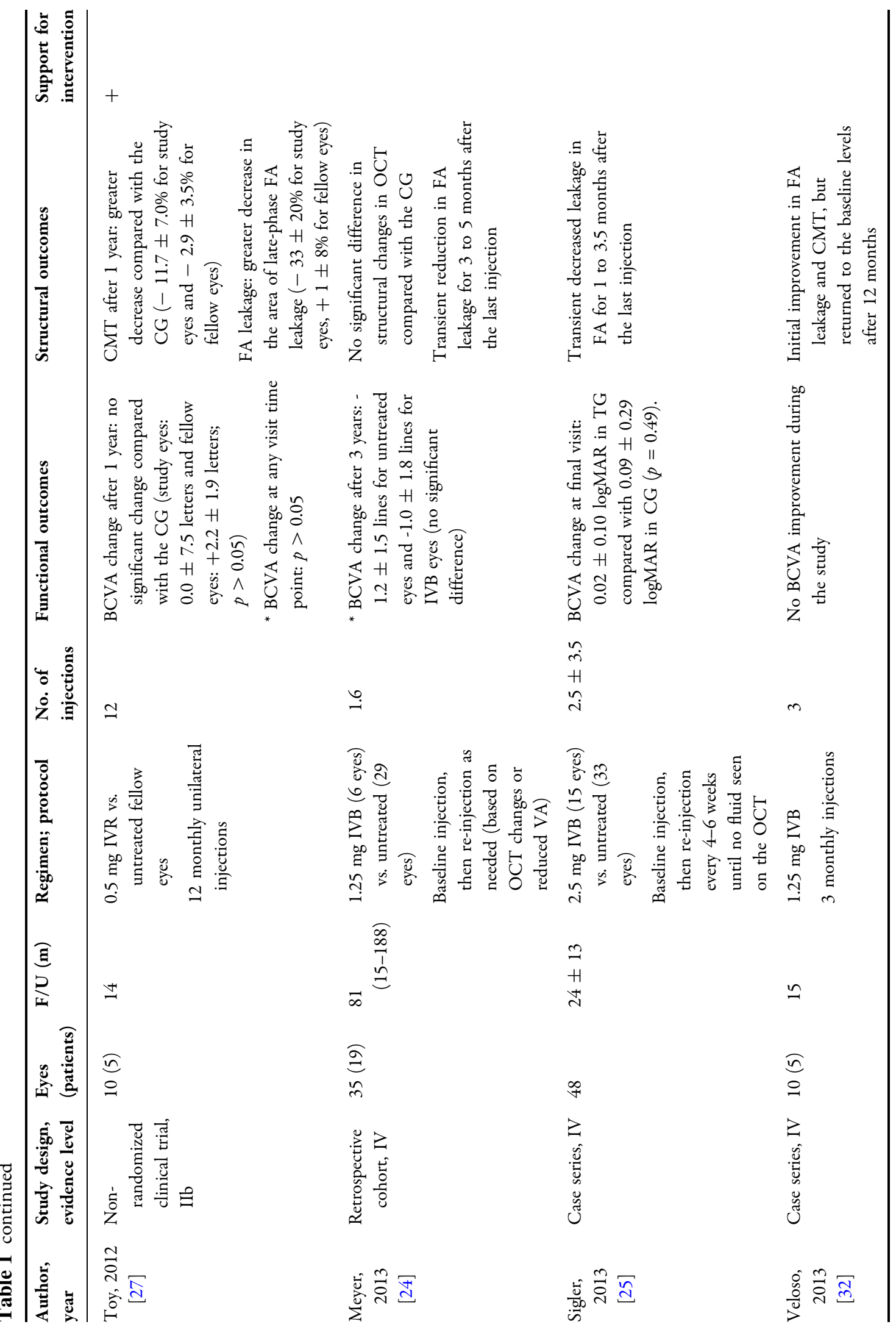




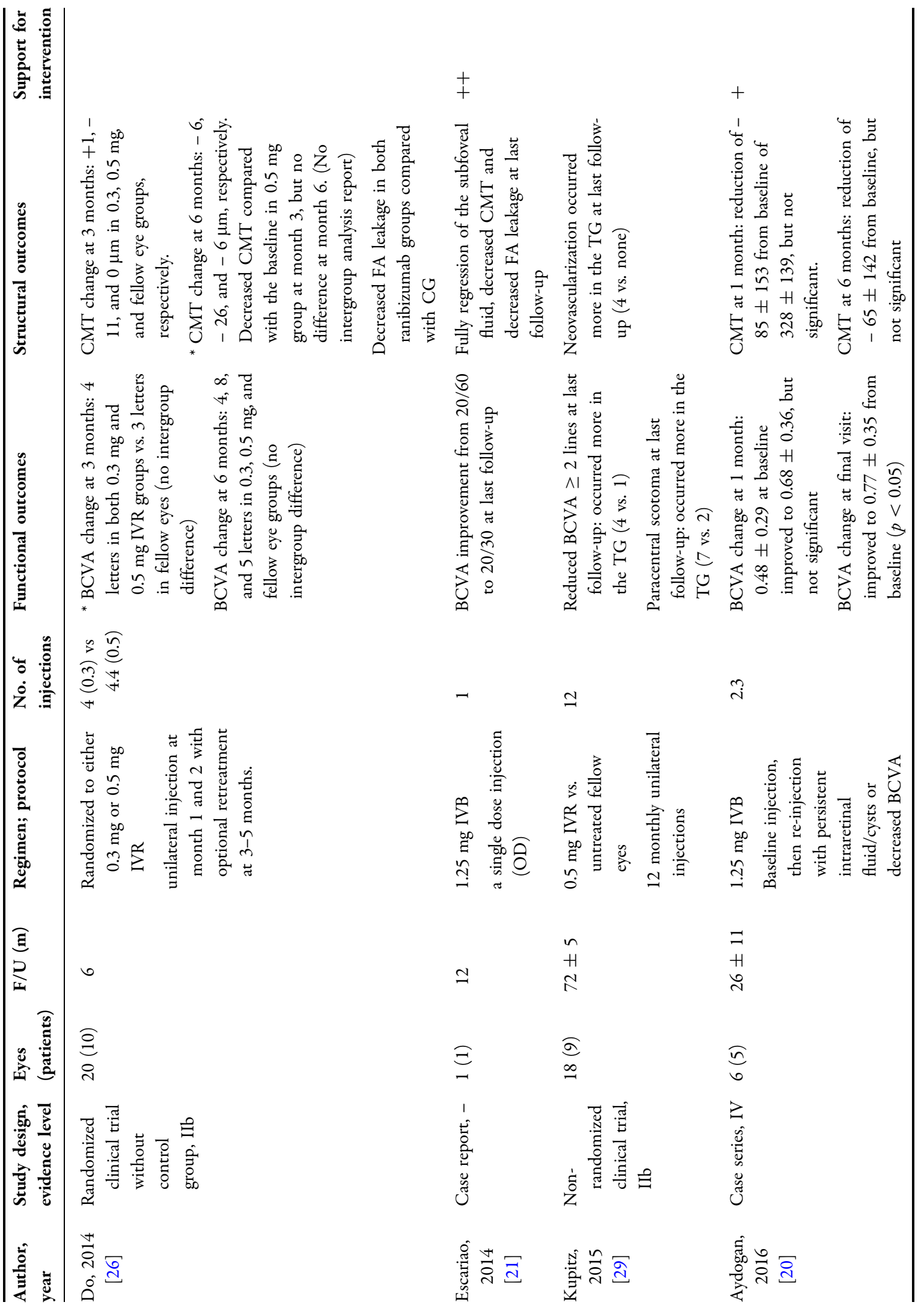




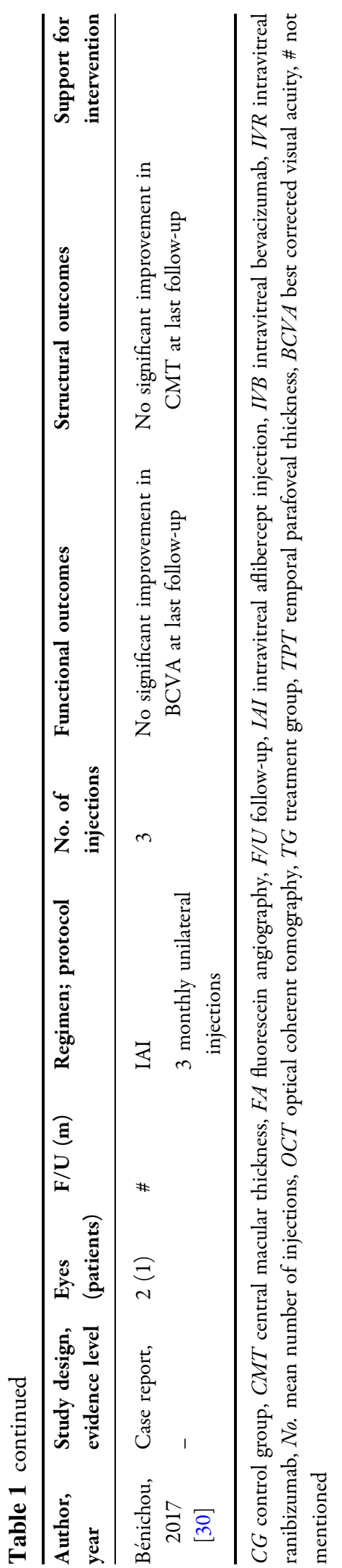

photocoagulation (ICG-DEP) with a significant reduction in CMT but no change in visual acuity at 4 months [39]. Combined PDT and intravitreal ranibizumab has also been described but without promising results [42].

\section{Pars Plana Vitrectomy (PPV)}

It has been theorized that some of the anatomical foveal changes in MacTel are the result of vitreous adhesion or traction on the retina. Pars plana vitrectomy (PPV) combined with internal limiting membrane (ILM) peeling was evaluated by Sigler et al. in a case series of five eyes [43]. Patients with foveal inner retinal cystic spaces compatible with lamellar macular hole configuration were selected. After 24 months, foveal cystic spaces persisted in four eyes-two eyes experienced no significant change in vision and two eyes had significant improvement in visual acuity-while one eye had decreased visual acuity due to a macular hole. Kimura et al. reported a case of MacTel with vitreomacular attachment and described the resolution of foveal cysts after spontaneous occurrence of total posterior vitreous detachment [44]. Patients with MacTel can develop full-thickness macular holes [45, 46], and surgically addressing these holes would be expected to improve some of the structural abnormalities. Nonetheless, full-thickness macular holes are infrequent, and caution is advised when assessing patients because large cystic cavities may resemble full-thickness macular holes ('lamellar hole'). While it may be tempting to try to surgically repair atrophic retinal cavities when they have the appearance of a lamellar hole, it is important to note that this will not address the underlying neurodegenerative nature of this disease, which is the root of the visual impairment. Abnormalities of the vitreomacular interface such as epiretinal membranes (ERM) and vitreomacular traction (VMT) are not considered features of MacTel, although they may contribute to the apparent size of low reflective inner retinal spaces (as well as to patients' subjective metamorphopsia). MacTel is not a stand-alone indication for macular surgery, and any PPV in these patients 


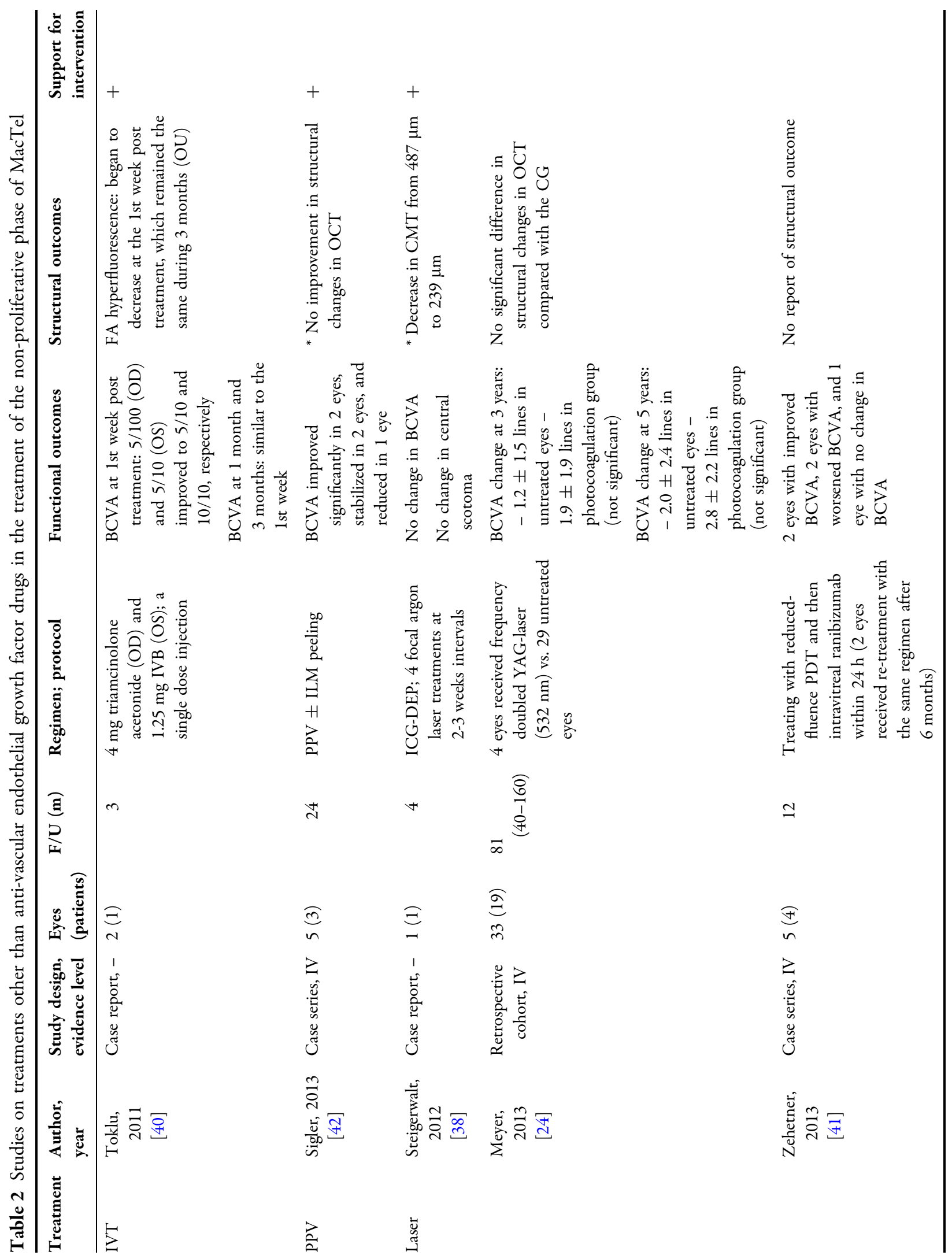




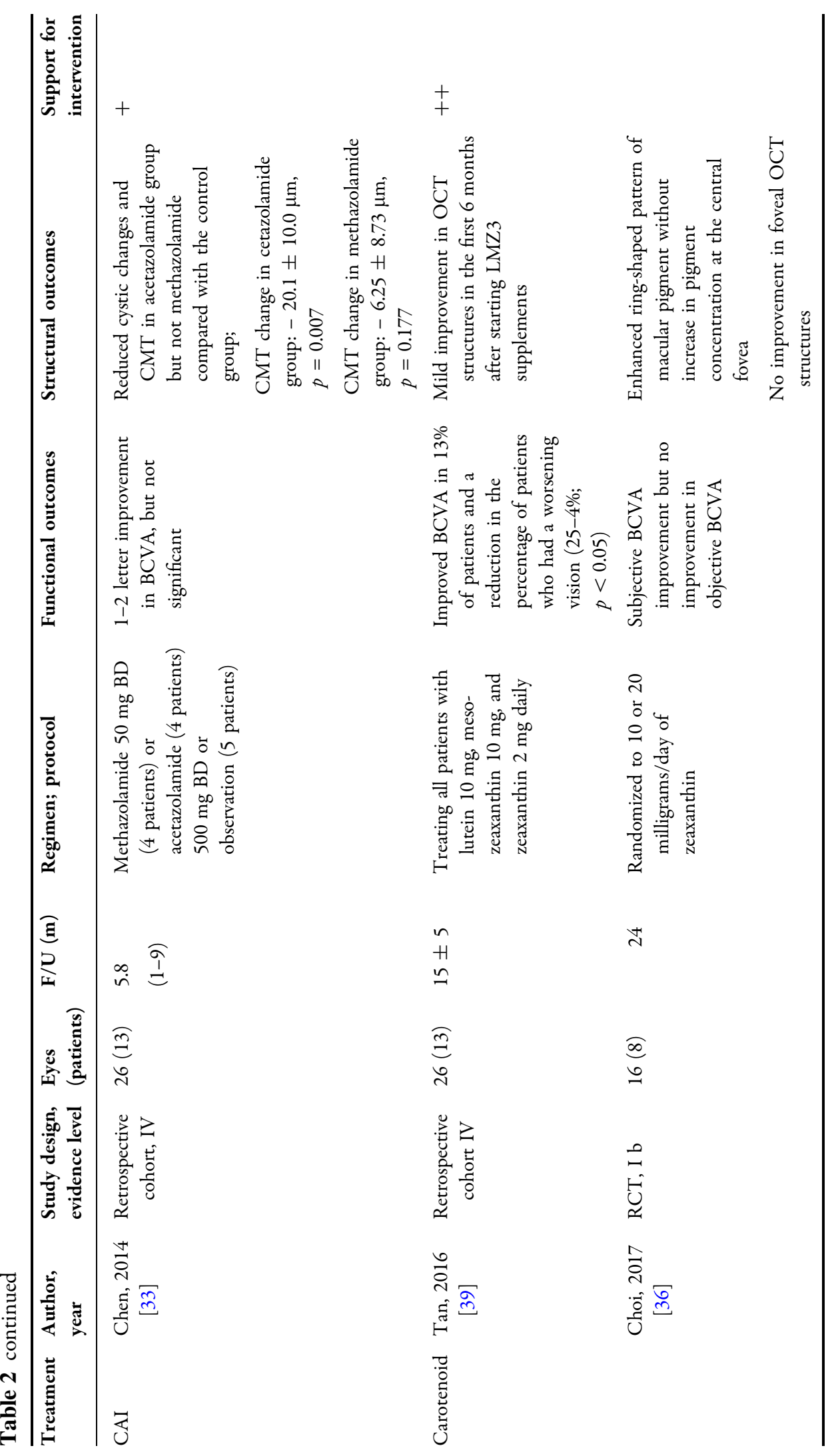




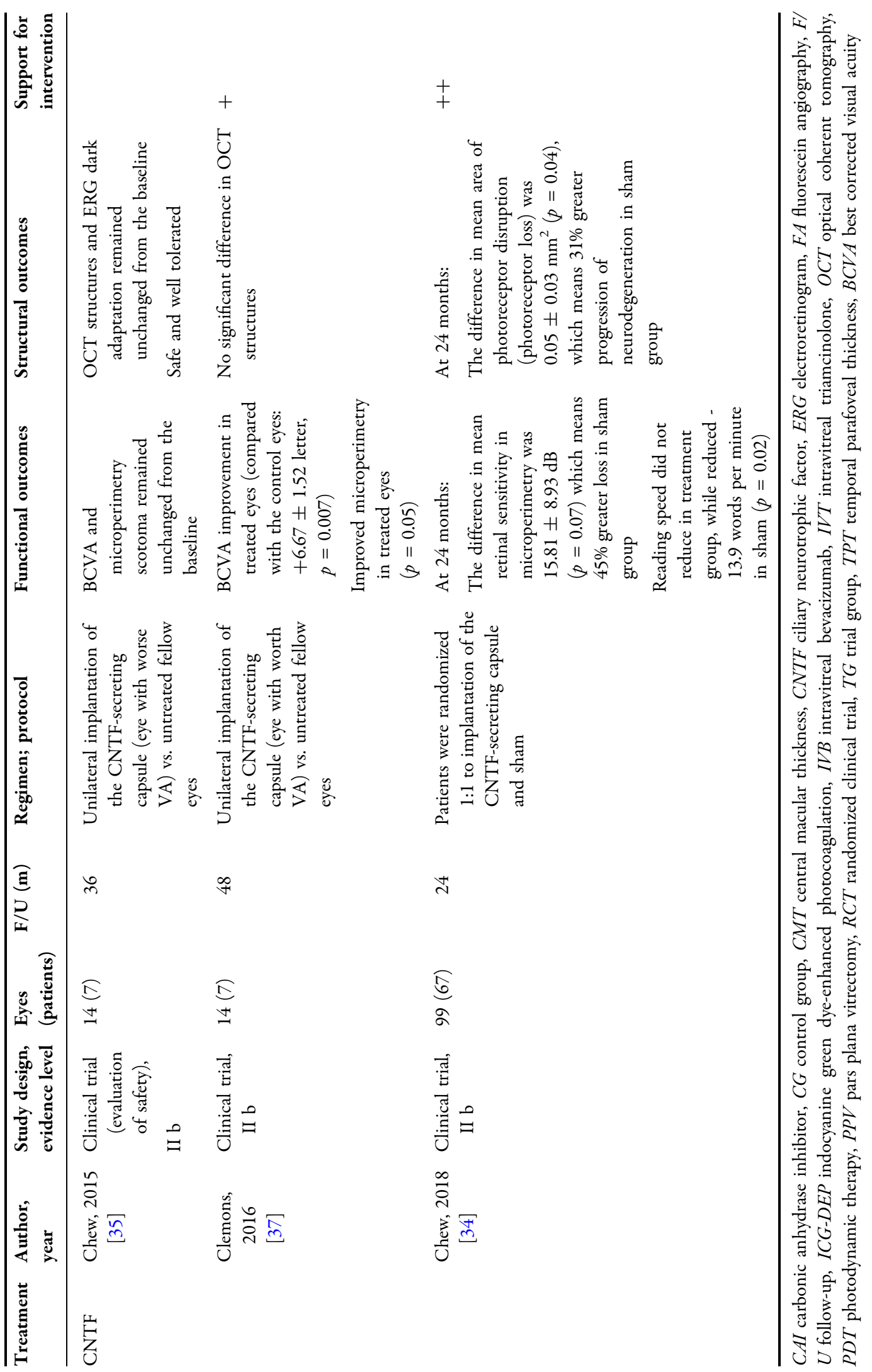


should be done to address concomitant retinal pathology and not MacTel.

\section{Carbonic Anhydrase Inhibitors (CAI)}

Carbonic anhydrase inhibitor (CAI) has been used in treating macular edema and cystic changes in retinitis pigmentosa and X-linked retinoschisis patients $[47,48]$. Chen et al. conducted a retrospective study on 26 eyes with MacTel who received systemic acetazolamide or methazolamide versus observation [34]. Interestingly, the cystic changes improved with acetazolamide but not with methazolamide; however, neither group experienced significant changes in vision compared with a control group. There are no apparent studies on the use of topical CAI. Given the lack of visual benefit in Chen et al.'s limited series, there does not appear to be significant utility to treating MacTel with CAI.

\section{Carotenoids}

One of the earliest examination findings in MacTel is the redistribution of macular carotenoid pigment beginning with a triangular segment of reduced macular pigment at the temporal fovea and a central accumulation of pigment, progressing to oval effacement of the central pigment and an enhanced surrounding ring of pigment. Carotenoid pigment rearrangement is consistent with the slowly progressive nature of this disease $[49,50]$. Macular pigment density was previously shown to be enhanced in patients with non-exudative agerelated macular degeneration treated with lutein and zeaxanthin supplementation [51], and this principle has been applied to patients with MacTel in two studies [37, 40]. Tan et al. treated patients with lutein, meso-zeaxanthin, and zeaxanthin [40] and found both functional and structural improvement during 15 months of follow-up. By contrast, patients in Choi et al.'s randomized clinical trial treated with zeaxanthin did not demonstrate a significant objective improvement in vision (although subjective improvement in vision was reported).
Although patients had an enhanced (increased density) ring-shaped pattern of perifoveal macular pigment, no enhancement occurred at the central fovea where the pigment was absent [37]. The results of these conflicting studies are not entirely comparable given the different treatment regimens. Nonetheless, larger randomized clinical trials are necessary to examine the role of carotenoid supplementation.

\section{Ciliary Neurotrophic Factor (CNTF)}

Photoreceptor loss is intrinsic to MacTel. Targeting neurogenerative pathways in the treatment of the non-proliferative phase of MacTel makes intuitive sense. Ciliary neurotrophic factor (CNTF) has been found to slow photoreceptor loss in animal models [52] and plays a role in the regeneration of the cone outer segment in experimental studies [53]. The NT-501 implant (Neurotech USA, Cumberland, RI, USA) uses encapsulated cell technology implanted into the eye with the ability to produce sustained CNTF release. Phase I clinical trial results demonstrated the safety of this treatment in patients with MacTel after 36 months based on electroretinogram changes, BCVA, microperimetry, and OCT [36]. Clemons et al. followed these after 48 months and reported significant functional improvement. Compared with the baseline, CNTF-treated eyes gained vision $(+1.17 \pm 0.48$ letters, $p=0.06)$ while control eyes lost vision $(-5.50 \pm 1.88$ letters, $p=0.03)$ [38]. The difference between the two groups was significant $(6.67 \pm 1.52 ; 95 \%$ CI $2.32-9.13 ; p=0.007)$. This was accompanied by an improvement in microperimetry results $(p=0.05)$; however, no structural improvement was seen. Phase II results, based on 99 eyes assigned randomly to either sham or treatment, demonstrated significantly less photoreceptor loss, fewer increases in ellipsoid zone discontinuity $(p=0.04)$, and better reading speeds $(p=0.02)$ at 24 months in patients treated with CNTF compared with the sham group. The incidence of serious adverse ocular effects was similar in the two study groups [35]. 


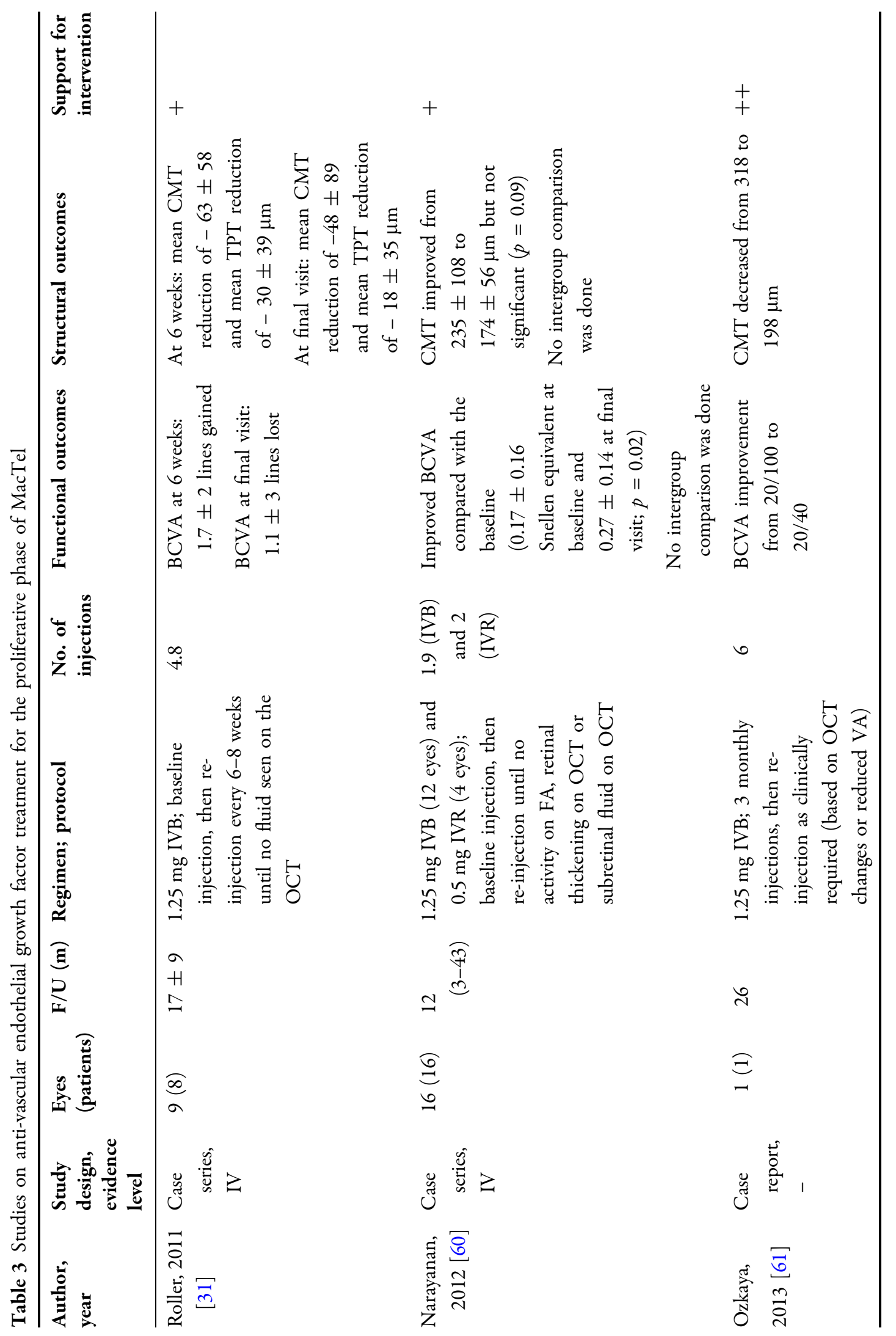




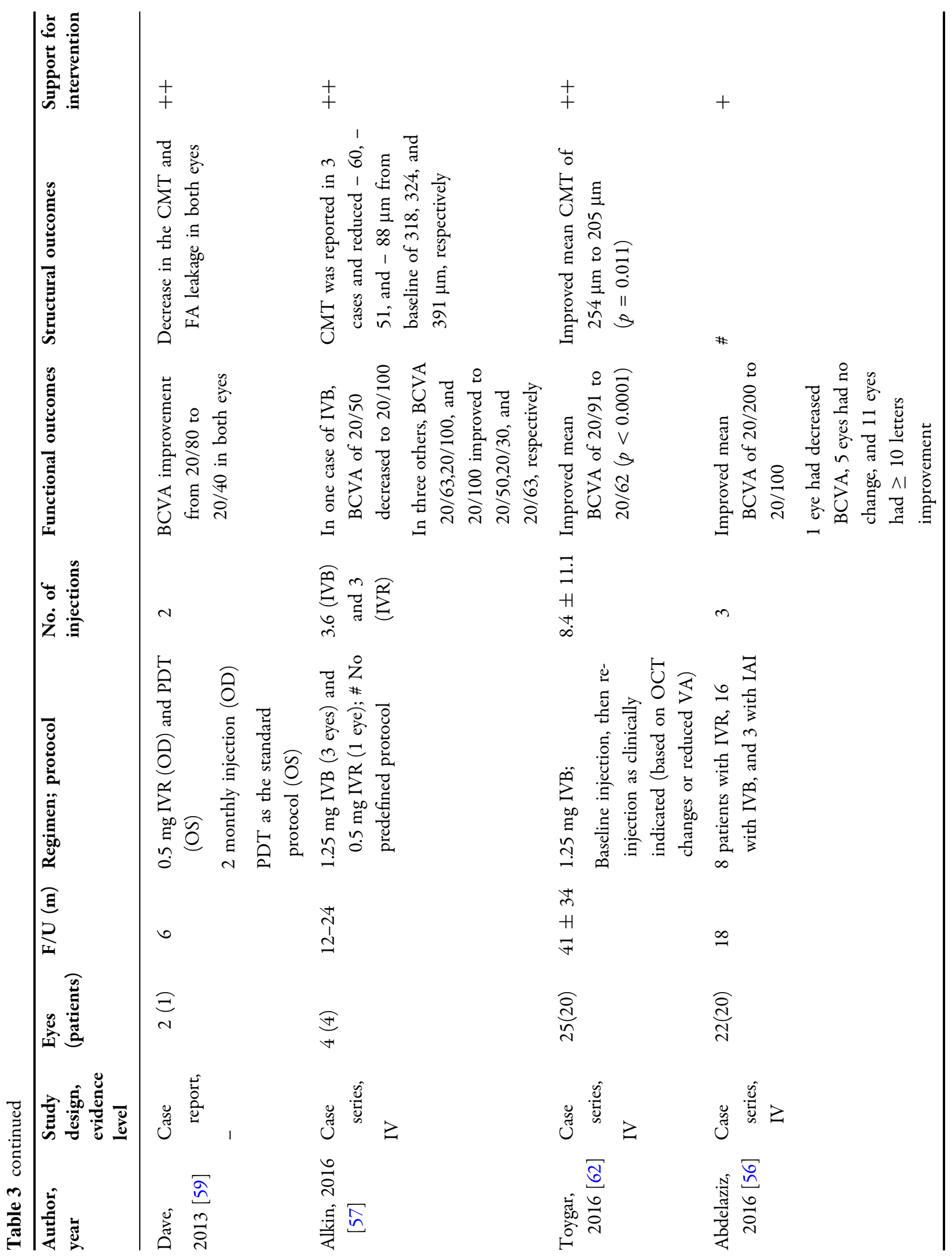




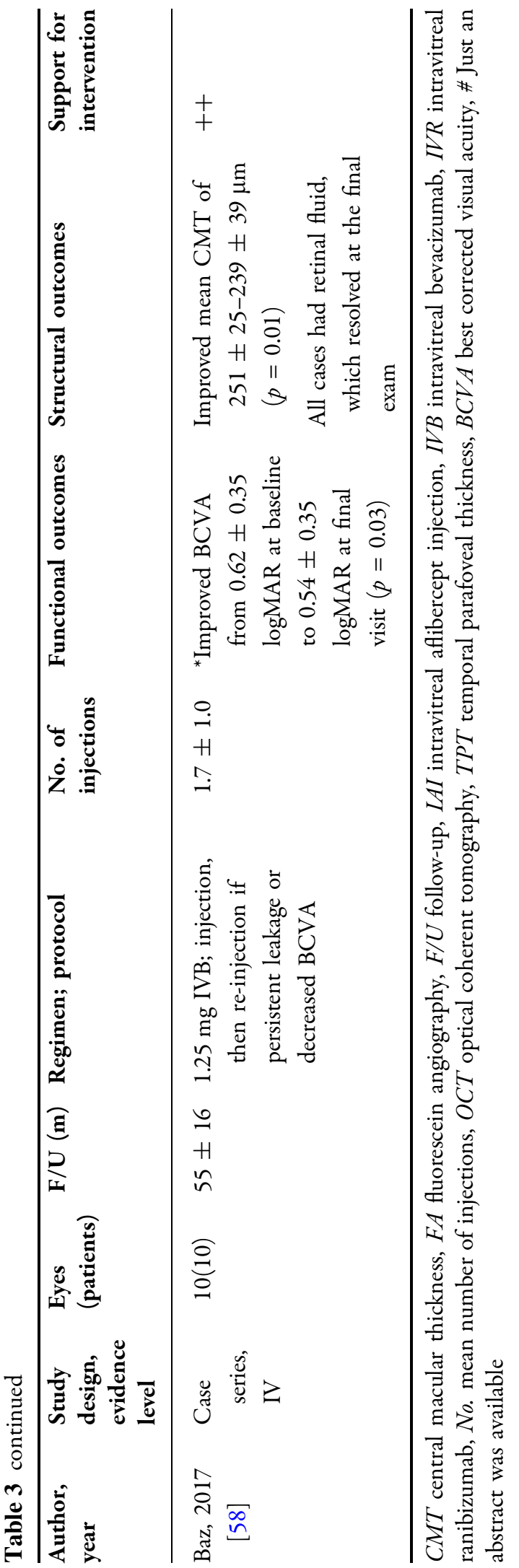

\section{Treatment of Proliferative Phase}

Most of studies examining the treatment of the proliferative phase of MacTel follow the paradigm set out in the treatment of other retinal neovascular disease processes. Subretinal surgery to remove the neovascular membrane was attempted but eventually abandoned because of strong adherence of the neovascular membrane to the retina and poor visual outcomes [54]. Argon laser photocoagulation was successful in ablating neovascularization, but large parafoveal scars were associated with profoundly impaired reading ability [10]. Photodynamic therapy (PDT) has been evaluated in several studies. The largest case series of PDT was conducted by Potter et al. on seven eyes, and they reported VA stabilization in six eyes [55]. Transpupillary thermotherapy (TTT) was studied in an interventional case series [56] with complete regression of neovascular membranes occurring in $85 \%$ of 13 eyes at 3 months.

Anti-VEGF agents are the established standard of care for most retinal vascular conditions. In our literature search, all studies examining the treatment of the proliferative phase of MacTel in the past decade were related to anti-VEGF therapy (Table 3) [32, 57-63]. By 2010 , there were some case reports on the efficacy of combined PDT and anti-VEGF regimens $[64,65]$; however, the more contemporary literature reviewed herein (since 2010) only had one case report by Dave et al. of one eye treated with PDT 4 years before bevacizumab injection in the other eye [60].

Most of studies of anti-VEGF therapy for the proliferative phase of MacTel reported the anatomical and functional improvement (Table 3). Only one retrospective study by Roller et al. reported borderline results [32] with improvement in visual acuity and CMT at 6 weeks but a mean reduction in BCVA of 0.5 lines after a mean follow-up time of 17.9 months; however, other studies [63] [59] have provided support for long-term structural and functional efficacy of anti-VEGF drugs (Fig. 2). The use of ranibizumab and aflibercept has also been described with good outcomes [57]. 


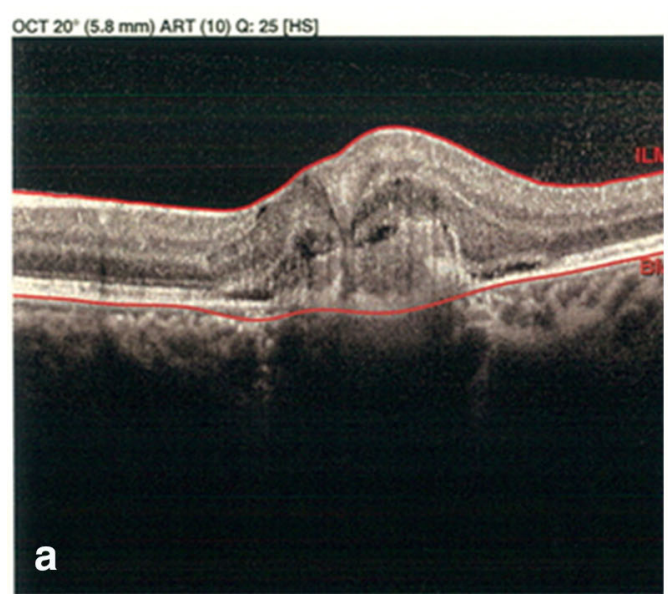

Fig. 2 MacTel proliferative phase treated with AntiVEGF. The same patient mentioned in Fig. 1c, d with active choroidal neovascularization and visual acuity of 20/200 underwent 3 monthly doses of intravitreal

\section{DISCUSSION}

In this study, the recent literature examining MacTel treatment was reviewed. The Yannuzzi classification of MacTel appears to be compatible with pathophysiology of this disease and correlates strongly with treatment strategies. The non-proliferative phase is primarily driven by neurodegenerative processes. Although cystic changes are seen within the retina, these are the result of degenerative tissue loss rather than active exudation, and therefore anti-VEGF treatment would not be expected to have meaningful results for the non-proliferative phase of MacTel. This has been confirmed in clinical trials and retrospective studies of antiVEGF therapy, which failed to show significant efficacy for either functional or structural improvement in this disease stage. Conversely, anti-VEGF treatment has been found to be successful in the treatment of the proliferative forms of MacTel and should be considered the first-line strategy given the consistent evidence supporting its use. Further studies examining whether there is a difference in response based on anti-VEGF agent and exploring different treatment schedules are needed to fully refine our understanding of anti-VEGF treatment for the proliferative phase of MacTel.

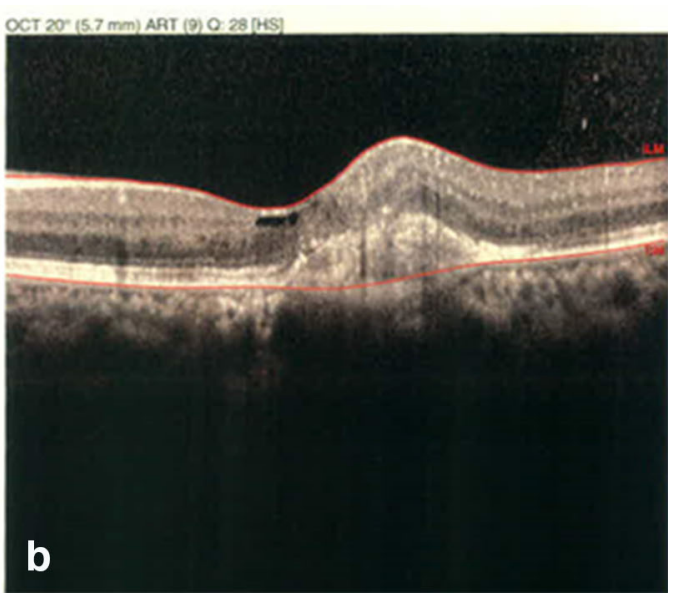

bevacizumab (a). After 3 months, most of the fluid was resolved with visual acuity improvement to 60/200 (b). Images courtesy of Dr. Hamid Riazi

Neuroprotective agents are theoretically appealing options for the non-proliferative phase of MacTel. Carotenoid supplementation has demonstrated mixed results perhaps due to differences in study design. There are many possible supplementation regimens, which can differ in components and dosage, and as such further study is necessary to determine which (if any) have value in the treatment of MacTel. Although initial CNTF trial data have been promising, longer term results are needed to fully assess CNTF's possible role in the treatment of MacTel. The natural history of MacTel involves the long-term loss of retinal thickness due to degenerative changes. This is an important consideration when examining the efficacy of different treatments and was rarely factored into previous reports. Arresting the otherwise progressive nature of the disease is an important goal since the reversal of tissue loss is typically not possible in retinal disease.

There are multiple reports suggesting genetic factors play a role in MacTel [66]. A genomewide linkage analysis identified a peak on chromosome 1 at 1q41-42 [67], but no causal variant was recognized in this region. A better understanding of the possible genetic factors in MacTel may allow for the development of animal models and provide new therapeutic 
approaches including targeted gene therapy. To date, there are no reported attempts to treat MacTel with gene therapy or stem cells.

Advances in imaging have revolutionized the evaluation of MacTel. Improvements in existing imaging technology and the development of new imaging platforms, such as OCT angiography, may provide new insights into MacTel's pathogenesis and may also give new end points for future studies.

The scoring used in this study was designed to highlight functional and structural improvements provided by each intervention. No comparison can be done on CMT or VA between different studies because of differences in evidence levels, sample sizes, and follow-up intervals. There is currently no level I evidence supporting MacTel treatments. The rarity of this disease makes designing randomized controlled studies difficult and necessitates the use of multicenter trials to allow for sufficient enrollment to achieve the necessary statistical power. Determining possible treatment regimens will take a collaborative and wide-scale approach.

\section{ACKNOWLEDGEMENTS}

The authors wish to thank Dr. Hamid Riazi for providing Figs. 1 and 2 for this manuscript.

Funding. No funding or sponsorship was received for this study or publication of this article.

Authorship. All named authors meet the International Committee of Medical Journal Editors (ICMJE) criteria for authorship for this article, take responsibility for the integrity of the work as a whole, and have given their approval for this version to be published.

Author Contributions. Concept and design: AKh, RR, JZ, MM; data acquisition: JZ, MM, HZ, ShK; data analysis/interpretation: MM, BM; drafting manuscript: MM, HZ, ShK, JZ; critical revision of manuscript: AKh, RR, BM, MM; supervision: AKh, RR, BM. All authors read and approved the final manuscript.
Disclosures: Alireza Khodabande, Ramak Roohipoor, Javad Zamani, Masoud Mirghorbani, Hamidreza Zolfaghari, Shahab Karami, and Bobeck S. Modjtahedi have nothing to disclose.

Compliance with Ethics Guidelines. This study is based on previously conducted studies. The study does not contain any studies with human participants or animals performed by any of the authors.

Open Access. This article is distributed under the terms of the Creative Commons Attribution-NonCommercial 4.0 International License (http://creativecommons.org/licenses/ by-nc/4.0/), which permits any noncommercial use, distribution, and reproduction in any medium, provided you give appropriate credit to the original author(s) and the source, provide a link to the Creative Commons license, and indicate if changes were made.

\section{REFERENCES}

1. Charbel Issa P, Gillies MC, Chew EY, Bird AC, Heeren TF, Peto T, et al. Macular telangiectasia type 2. Progr Retinal Eye Res. 2013;34:49-77.

2. Clemons TE, Gillies MC, Chew EY, Bird AC, Peto T, Figueroa MJ et al. Baseline characteristics of participants in the natural history study of macular telangiectasia (MacTel) MacTel Project Report No. 2. Ophthalmic epidemiology 2010; 17(1): 66-73.

3. Gass JD, Blodi BA. Idiopathic juxtafoveolar retinal telangiectasis. 1993;100(10):1536-46. Ophthalmology.

4. Gass JD, Oyakawa RT. Idiopathic juxtafoveolar retinal telangiectasis. Arch Ophthalmol (Chicago, Ill : 1960). 1982;100(5):769-80.

5. Yannuzzi LA, Bardal AMC, Freund $\mathrm{KB}$, Chen $\mathrm{KJ}$, Eandi CM, Blodi B. Idiopathic macular telangiectasia. Arch Ophthalmol. 2006;124(4):450-60.

6. Chatziralli IP, Sharma PK, Sivaprasad S. treatment modalities for idiopathic macular telangiectasia: an evidence-based systematic review of the literature. Semin Ophthalmol. 2017;32(3):384-94.

7. Klein R, Blodi BA, Meuer SM, Myers CE, Chew EY, Klein BEK. The prevalence of macular telangiectasia 
type 2 in the beaver dam eye study. Am J Ophthalmol. 2010;150(1):55-62.e52.

8. Scerri TS, Quaglieri A, Cai C, Zernant J, Matsunami $\mathrm{N}$, Baird L, et al. Genome-wide analyses identify common variants associated with macular telangiectasia type 2. Nat Genet. 2017;49(4):559-67.

9. Heeren TF, Clemons T, Scholl HP, Bird AC, Holz FG, Charbel Issa P. Progression of vision loss in macular telangiectasia type 2 . Invest Ophthalmol Vis Sci. 2015;56(6):3905-12.

10. Vaze A, Gillies M. Salient features and management options of macular telangiectasia type 2: a review and update. Expert Rev Ophthalmol. 2016;11(6):429-41.

11. Klein R, Blodi BA, Meuer SM, Myers CE, Chew EY, Klein BE. The prevalence of macular telangiectasia type 2 in the Beaver Dam eye study. Am J Ophthalmol. 2010;150(1):55-62.e52.

12. Powner MB, Scott A, Zhu M, Munro PM, Foss AJ, Hageman GS, et al. Basement membrane changes in capillaries of the ageing human retina. $\mathrm{Br} \mathrm{J}$ Ophthalmol. 2011;95(9):1316-22.

13. Powner MB, Gillies MC, Tretiach M, Scott A, Guymer RH, Hageman GS, et al. Perifoveal müller cell depletion in a case of macular telangiectasia type 2 . Ophthalmology. 2010;117(12):2407-16.

14. Charbel Issa P, Gillies MC, Chew EY, Bird AC, Heeren TFC, Peto T, et al. Macular telangiectasia type 2. Progr Retinal Eye Res. 2013;34:49-77.

15. Spaide RF, Klancnik JM Jr, Cooney MJ. Retinal vascular layers in macular telangiectasia type 2 imaged by optical coherence tomographic angiography. JAMA Ophthalmol. 2015;133(1):66-73.

16. Goldman D. Muller glial cell reprogramming and retina regeneration. Nat Rev Neurosci. 2014;15(7):431-42.

17. Shen W, Fruttiger M, Zhu L, Chung SH, Barnett NL, Kirk JK, et al. Conditional Müller cell ablation causes independent neuronal and vascular pathologies in a novel transgenic model. J Neurosci. 2012;32(45):15715-27.

18. Oxford Centre for Evidence Based Medicine-Levels of evidence; 2009. Available at: https://www. cebmnet/index. Accessed 10 June 2018.

19. De Lahitte GD, Cohen SY, Gaudric A. Lack of apparent short-term benefit of photodynamic therapy in bilateral, acquired, parafoveal telangiectasis without subretinal neovascularization. Am J Ophthalmol. 2004;138(5):892-4.
20. Eandi CM, Ober MD, Freund KB, Klais CM, Slakter JS, Sorenson JA, et al. Anecortave acetate for the treatment of idiopathic perifoveal telangiectasia: a pilot study. Retina (Philadelphia, Pa). 2006;26(7):780-5.

21. Aydogan T, Erdogan G, Unlu C, Ergin A. Intravitreal Bevacizumab Treatment in Type 2 Idiopathic Macular Telangiectasia. Turkish journal of ophthalmology. 2016;46(6):270-3.

22. Escarião $\mathrm{P}$, Arcoverde $\mathrm{AL}$, Mendes R, Araujo EH. Intravitreal bevacizumab therapy for idiophatic juxtafoveolar retinal telangiectasis associated with serous macular detachment. Revista Brasileira de Oftalmologia. 2014;73(1):47-9.

23. Lira RP, Silva VB, Cavalcanti TM, de Souza AC, Pinto AP. Intravitreous ranibizumab as treatment for macular telangiectasia type 2. Arch Ophthalmol(Chicago, Ill : 1960). 2010;128(8):1075-8.

24. Matt G, Sacu S, Ahlers C, Schütze C, Dunavoelgyi R, Prager F, et al. Thirty-month follow-up after intravitreal bevacizumab in progressive idiopathic macular telangiectasia type 2. Eye. 2010;24(10):1535-42.

25. Meyer-Ter-Vehn T, Herzog S, Schargus M, Göbel W, Guthoff R. Long-term course in type 2 idiopathic macular telangiectasia. Graefe's Arch Clin Exp Ophthalmol. 2013;251(11):2513-20.

26. Sigler EJ, Randolph JC, Calzada JI, Charles S. Comparison of observation, intravitreal bevacizumab, or pars plana vitrectomy for non-proliferative type 2 idiopathic macular telangiectasia. Graefe's Arch Clin Exp Ophthalmol Albrecht von Graefes Archiv fur klinische und experimentelle Ophthalmologie. 2013;251(4):1097-101.

27. Do DV, Bressler SB, Cassard SD, Gower EW, Tabandeh H, Jefferys JL, et al. Ranibizumab for macular telangiectasia type 2 in the absence of subretinal neovascularization. Retina (Philadelphia, Pa). 2014;34:2063-71.

28. Toy BC, Koo E, Cukras C, Meyerle CB, Chew EY, Wong WT. Treatment of nonneovascular idiopathic macular telangiectasia type 2 with intravitreal ranibizumab: results of a phase II clinical trial. Retina (Philadelphia, Pa). 2012;32(5):996-1006.

29. Charbel Issa P, Finger RP, Kruse K, Baumuller S, Scholl HP, Holz FG. Monthly ranibizumab for nonproliferative macular telangiectasia type 2: a 12-month prospective study. Am J Ophthalmol. 2011;151(5):876-886.e871.

30. Kupitz EH, Heeren TFC, Holz FG, Issa PC. Poor longterm outcome of anti-vascular endothelial growth factor therapy in nonproliferative macular 
telangiectasia type 2. Retina (Philadelphia, Pa). 2015;35:2619-26.

31. Bénichou J, Soler V, Denis D, Matonti F. Inefficacy of aflibercept in the treatment of idiopathic macular telangiectasia type 2 without neovascularization. J Fr Ophtalmol. 2017;40(7):547-51.

32. Roller AB, Folk JC, Patel NM, Boldt HC, Russell SR, Abramoff $\mathrm{MD}$, et al. Intravitreal bevacizumab for treatment of proliferative and nonproliferative type 2 idiopathic macular telangiectasia. Retina (Philadelphia, Pa). 2011;31(9):1848-55.

33. Veloso CE, Vianna RN, Pelayes DE, Nehemy MB. Intravitreal bevacizumab for type 2 idiopathic macular telangiectasia. Ophthal Res. $2013 ; 49(4): 205-8$.

34. Chen JJ, Sohn EH, Folk JC, Mahajan VB, Kay CN, Boldt HC, et al. Decreased macular thickness in nonproliferative macular telangiectasia type 2 with oral carbonic anhydrase inhibitors. Retina (Philadelphia, Pa). 2014;34(7):1400-6.

35. Chew EY, Clemons TE, Jaffe GJ, Johnson CA, Farsiu $\mathrm{S}$, Lad EM et al. Effect of ciliary neurotrophic factor on retinal neurodegeneration in patients with macular telangiectasia type 2: a randomized clinical trial. Ophthalmology 2018. https://doi.org/10. 1016/j.ophtha.2018.09.041.

36. Chew EY, Clemons TE, Peto T, Sallo FB, Ingerman A, Tao W, et al. Ciliary neurotrophic factor for macular telangiectasia type 2: results from a phase 1 safety trial. Am J Ophthalmol. 2015;159(4):659-666.e651.

37. Choi RY, Gorusupudi A, Wegner K, Sharifzadeh M, Gellermann W, Bernstein PS. Macular pigment distribution responses to high-dose zeaxanthin supplementation in patients with macular telangiectasia type 2. Retina (Philadelphia, Pa). 2017;37(12):2238-2247.

38. Clemons TE, Chew EY, Peto T, Sallo FB, Leung I. Ciliary neurotrophic factor for macular telangiectasia type 2: 48 month results from the phase 1 safety trial. In: Investigative ophthalmology and visual science conference: 2016 annual meeting of the association for research in vision and ophthalmology, ARVO 2016 United states, 2016; 57:2038.

39. Steigerwalt RD Jr, Pascarella A, Arrico L, Librando A, Plateroti R, Plateroti AM, et al. Idiopathic juxtafoveal retinal telangiectasis and retinal macroaneurysm treated with indocyanine green dyeenhanced photocoagulation. Panminerva Med. 2012;54(4 Suppl. 1):93-6.

40. Tan ACS, Balaratnasingam C, Yannuzzi LA. Treatment of macular telangiectasia type 2 with carotenoid supplements containing meso-zeaxanthin: a pilot study. Ophthal Surg Lasers Imaging Retina. 2016;47:528-35.

41. Toklu Y, Raza S, Anayol MA, Özkan B, Altintaş AK, Şimşek S. Comparison between efficacy of triamcinolone acetonide and bevacizumab in a case with type $2 \mathrm{~A}$ idiopathic parafoveal telangiectasia. Turk Oftalmoloiji Dergisi. 2011;41(1):6-9.

42. Zehetner C, Haas G, Treiblmayr B, Kieselbach GF, Kralinger MT. Reduced-fluence photodynamic therapy combined with ranibizumab for nonproliferative macular telangiectasia type 2 . Ophthalmol J Int d'ophtalmologie Int $\mathrm{J}$ Ophthalmol Zeitschrift fur Augenheilkunde. 2013;229(4):195-202.

43. Sigler EJ, Randolph JC, Calzada JI, Charles S. Pars plana vitrectomy with internal limiting membrane removal in type 2 idiopathic macular telangiectasia. Retinal Cases Brief Rep. 2013;7(4):380-5.

44. Kimura M, Koizumi H, Maruko I, Iida T. Resolution of foveal cyst after the release of vitreomacular attachment in eye with macular telangiectasia type 2. Retinal Cases Brief Rep. 2017. https://doi.org/10. 1097/ICB.0000000000000561.

45. Gregori N, Flynn HW Jr. Surgery for full-thickness macular hole in patients with idiopathic macular telangiectasia type 2. Ophthal Surg Lasers Imaging. 2010;41:1-4.

46. Shukla D, Venkatesh R. Spontaneous closure of fullthickness macular hole in type 2 idiopathic macular telangiectasia. Graefe's Archi Clin Exp Ophthalmol Albrecht von Graefes Archiv fur klinische und experimentelle Ophthalmologie. 2012;250(11):1711-2.

47. Genead MA, Fishman GA. Efficacy of sustained topical dorzolamide therapy for cystic macular lesions in patients with retinitis pigmentosa and usher syndrome. Arch Ophthalmol (Chicago, Ill : 1960). 2010;128(9):1146-50.

48. Genead MA, Fishman GA, Walia S. Efficacy of sustained topical dorzolamide therapy for cystic macular lesions in patients with X-linked retinoschisis. Arch Ophthalmol (Chicago, Ill : 1960). 2010;128(2):190-7.

49. Zeimer MB, Kromer I, Spital G, Lommatzsch A, Pauleikhoff D. Macular telangiectasia: patterns of distribution of macular pigment and response to supplementation. Retina (Philadelphia, PA). 2010;30(8):1282-93.

50. Zeimer MB, Padge B, Heimes B, Pauleikhoff D. Idiopathic macular telangiectasia type 2: 
distribution of macular pigment and functional investigations. Retina (Philadelphia, PA). 2010;30(4):586-95.

51. Dawczynski J, Jentsch S, Schweitzer D, Hammer M, Lang GE, Strobel J. Long term effects of lutein, zeaxanthin and omega-3-LCPUFAs supplementation on optical density of macular pigment in AMD patients: the LUTEGA study. Graefe's Archi Clin Exp Ophthalmol Albrecht von Graefes Archiv fur klinische und experimentelle Ophthalmologie. 2013;251(12):2711-23.

52. Cayouette M, Gravel C. Adenovirus-mediated gene transfer of ciliary neurotrophic factor can prevent photoreceptor degeneration in the retinal degeneration (rd) mouse. Hum Gene Ther. 1997;8(4):423-30.

53. Li Y, Tao W, Luo L, Huang D, Kauper K, Stabila P, et al. CNTF induces regeneration of cone outer segments in a rat model of retinal degeneration. PLoS One. 2010;5(3):e9495.

54. Berger AS, McCuen BW, Brown GC, Brownlow RL. Surgical removal of subfoveal neovascularization in idiopathic juxtafoveolar retinal telangiectasis. Retina (Philadelphia, Pa). 1997;17(2):94-8.

55. Potter MJ, Szabo SM, Chan EY, Morris AH. Photodynamic therapy of a subretinal neovascular membrane in type $2 \mathrm{~A}$ idiopathic juxtafoveolar retinal telangiectasis. Am J Ophthalmol. 2002;133(1):149-51.

56. Shukla D, Singh J, Kolluru CM, Kim R, Namperumalsamy P. Transpupillary thermotherapy for subfoveal neovascularization secondary to group $2 \mathrm{~A}$ idiopathic juxtafoveolar telangiectasis. Am J Ophthalmol. 2004;138(1):147-9.

57. Abdelaziz M, Rostamizadeh M, Schartman J, Zegarra $\mathrm{H}$, Zakov ZN, Novak M, et al. The use of anti-vascular endothelial growth factor therapies in the macular telangiectasia associated with choroidal neovascularization. Invest Ophthalmol Vis Sci. 2016;57(12):2145.

58. Alkin Z, Yilmaz I, Ozkaya A, Yazici A. Anti-vascular endothelial growth factor treatment for proliferative macular telangiectasia type 2. Middle East Afr J Ophthalmol. 2016;23(2):222-4.

59. Baz O, Yilmaz I, Alagoz C, Demircan A, Perente I, Ozkaya A, et al. Efficacy of intravitreal bevacizumab in treatment of proliferative type 2 idiopathic juxtafoveal telangiectasia. Turk J Ophthalmol. 2017;47(3):144-8.

60. Dave V, Chhablani J, Narayanan R. Different treatment modalities for choroidal neovascularization in two eyes of one patient with bilateral type $2 \mathrm{~A}$ parafoveal telangiectasia. Indian $\mathrm{J}$ Ophthalmol. 2013;61(7):353-5.

61. Narayanan R, Chhablani J, Sinha M, Dave V, Tyagi M, Pappuru RR, et al. Efficacy of anti-vascular endothelial growth factor therapy in subretinal neovascularization secondary to macular telangiectasia type 2. Retina (Philadelphia, PA). 2012;32(10):2001-5.

62. Ozkaya A, Alkin Z, Karakucuk Y, Yazici AT, Demirok A. Long term result of intravitreal bevacizumab in a patient newly transformed to proliferative macular telangiectasia type 2. Middle East Afr J Ophthalmol. 2013;20(4):360-2.

63. Toygar O, Guess MG, Youssef DS, Miller DM. LongTERM OUTCOMES OF INTRAVITREAL BEVACIZUMAB THERAPY FOR SUBRETINAL NEOVASCULARIZATION SECONDARY TO IDIOPATHIC MACULAR TELANGIECTASIA TYPE 2. Retina (Philadelphia, PA). 2016;36(11):2150-7.

64. Rishi P, Shroff D, Rishi E. Combined photodynamic therapy and intravitreal ranibizumab as primary treatment for subretinal neovascular membrane (SRNVM) associated with type 2 idiopathic macular telangiectasia. Graefe's Arch Clin Exp Ophthalmol Albrecht von Graefes Archiv fur klinische und experimentelle Ophthalmologie. 2008;246(4):619-21.

65. Smithen LM, Spaide RF. Photodynamic therapy and intravitreal triamcinolone for a subretinal neovascularization in bilateral idiopathic juxtafoveal telangiectasis. Am J Ophthalmol. 2004;138(5):884-5.

66. Issa PC, Gillies MC, Chew EY, Bird AC, Heeren TFC, Peto T, et al. Macular telangiectasia type 2. Progr Retinal Eye Res. 2013;34:49-77.

67. Parmalee NL, Schubert C, Figueroa M, Bird AC, Peto $\mathrm{T}$, Gillies $\mathrm{MC}$, et al. Identification of a potential susceptibility locus for macular telangiectasia type 2. PLoS One. 2012;7(8):e24268. 